\title{
MODELING AND PREDICTION OF SPECIFIC COMPOUND ADSORPTION BY ACTIVATED CARBON AND SYNTHETIC ADSORBENTS
}

\author{
B. M. VAN VLIeT ${ }^{1}$, W. J. Weber $\mathrm{JR}^{2}$ and H. HozUm ${ }^{3}$ \\ ${ }^{1}$ National Institute for Water Research, Pretoria, Republic of South Africa, \\ ${ }^{2}$ Environmental and Water Resources Engineering, The University of Michigan, \\ Ann Arbor, MI, U.S.A. and \\ ${ }^{3}$ Muroran Institute of Technology, Muroran, Hokkaido, Japan
}

(Received August 1979)

\begin{abstract}
Abatract-The performance characteristics of two activated carbons and eight synthetic adsorbents are compared. The comparison addresses both the equilibrium capacities and mass transport properties of the adsorbents. A new empirical adsorption isotherm is employed for description of adsorption equilibrium data. A predictive mathematical model is used for forecasting adsorption bed performance from independent batch reactor system data.
\end{abstract}

\section{INTRODUCTION}

The implications of organic residues in municipal and industrial wastewater discharges have been amplified by increasing water reuse-both planned and covert-and by mounting evidence of the bioaccumulation and adverse ecologic and public health impacts of certain compounds.

The efficacy of activated carbon treatment for removal of a diverse array of organic compounds not addressed by more conventional processes has been demonstrated. Recent interest has focused on potential applications of alternative and/or complementary synthetic adsorbents for specific compound removal. A number of different synthetic adsorbents have been employed for adsorption of organic compounds in a variety of applications, including groundwater purification (Wood, 1979), water treatment (Gauntlett, 1975; Neely, 1978), industrial waste treatment (Kennedy, 1973; Kunin, 1976), wastewater treatment (Kim et al., 1976), analytical chemistry (Chriswell et al., 1977; Junk et al., 1976; Leenheer \& Huffman, 1976) and therapeutic hemoperfusion treatment (Rosenbaum, 1975). Synthetic adsorbents have in certain instances been reported to equal or exceed the performance of activated carbon; in others carbon has proven superior.

A comprehensive review of the literature pertaining to synthetic adsorbents is beyond the scope of this paper, and the references given are intended merely as examples. Despite a rather broad base of experience with synthetic adsorbents and activated carbon, no systematic and definitive comparison of relative performance for removal of specific organic compounds from wastewaters has been advanced.

To develop a firm basis for evaluation and selection of different adsorbents for specific applications, a study was designed and executed at the University of
Michigan to elucidate and compare the performance of a representative series of eight synthetic adsorbents and two commercial activated carbons with respect to the removal of several classes of specific organic compounds. An array of six model solutes representing wide ranges of solubilities, molecular weights, molecular polarities and polarizabilities was selected for the comprehensive study.

This paper deals principally with the results for one of the solutes, phenol, and all ten adsorbents. The evaluation considers both adsorption equilibrium, or capacity, and kinetic or mass transport characteristics. Parameters derived from finite-bath, batchreactor equilibrium and kinetic studies are incorporated in a numeric-based predictive model for fixedbed adsorber design, and independent experimental data from fixed-bed adsorber runs are used to test the validity of the modeling results. Predictive models of this nature afford elegant means for comparison of different adsorbents under projected operating conditions. They are further capable of functioning as rational bases for adsorber design and for optimization of operating procedures.

\section{EXPERIMENTAL}

\section{Solute}

Reagent grade phenol (Mallinckrodt, Inc.) was employed in most experiments described herein. Experịmental solutions were prepared in deionized glass-distilled water with a $0.005 \mathrm{~N} \mathrm{NaHCO}$, buffer background at $\mathrm{pH} \sim 8.4$. All experiments were conducted at $22.5 \pm 1^{\circ} \mathrm{C}$. Phenol was analyzed by u.v. spectrophotometry at a wavelength of $268 \mathrm{~nm}$.

\section{Adsorbents}

The ten adsorbents used in this study included the two commercial activated carbons and eight synthetic adsorbents described below. 
Filtrasorb 400 activated carbon (Calgon Corporation); bituminous coal based; irregularly shaped granules.

BACM activated carbon (Mitsubishi Co.): pitch based; spherical beads.

Ambersorb XE-340, XE-347, XE-348 carbonaceous adsorbents (Rohm \& Haas Co.); carbonized polymers; spherical beads.

Amberlite XAD-2, and XAD-4 polymeric adsorbents (Rohm \& Haas, Co.); macroporous cross-linked polystyrene based; spherical beads.

Amberlite XAD-8 polymeric adsorbent (Rohm \& Haas, Co.); macroporous cross-linked polyacrylic ester based; spherical beads.

Duolite S-37 weakly-basic anion exchange resin (Diamond Shamrock Chemical $\mathrm{Co}$.); cross-linked phenol-formaldehyde based; irregularly shaped granules. Used as resinous adsorbent; i.e. in free-base form in this study.

Duolite ES-863 polymeric adsorbent (Diamond Shamrock Chemical Co.); polyvinyl based; spherical beads.

All adsorbents were sieved into a series of particle size fractions. The $0.30-0.42 \mathrm{~mm}$ size fractions were used throughout this study. The activated carbons were sieved dry, and the synthetic adsorbents sieved in a touch-dry, but not dehydrated, state. Following sieving the carbons were washed with deionized distilled water for removal of fines, dried for several days at $115^{\circ} \mathrm{C}$ and stored in dessicated sealed containers. The polymeric and carbonaceous adsorbents (XAD-2, XAD-4, XAD-8; XE-340, XE-347, XE-348 and ES-863) were successively washed (Rohm \& Haas Co., 1978) with deionized distilled water and methanol, thoroughly rinsed with the water, and stored under water at $4^{\circ} \mathrm{C}$ in sealed containers. The methanol served both to properly wet the hydrophobic synthetic adsorbents and to purify them of leachable organic residues, at least sufficiently so for the current (non-analytical) purposes. The resinous adsorbent, Duolite S-37, was successively washed (Diamond Shamrock Chemical Co., 1973), with $2.0 \mathrm{~N} \mathrm{HCl}$, $1.5 \mathrm{~N} \mathrm{NaOH}$, and deionized distilled water. The final water rinse was continued until the effluent $\mathrm{pH}$ approached that of the influent distilled water. The resin, in the free-base form, was stored under deionized distilled water at $4^{\circ} \mathrm{C}$ in a sealed container.

The activated carbons were weighed in the dry state for determination of specific amounts used in the experimental studies. The synthetic adsorbents, however, were stored under water, and a special procedure had to be followed to accurately prepare specific dosages. Wet adsorbent was placed in a $15-\mathrm{ml}$ coarse sintered glass funnel, which fitted snugly into a wooden support sleeve. The funnel was capped, and the complete assembly centrifuged at $4000 \mathrm{rev} /$ min for $2 \mathrm{~min}$. The funnel cover prevented drying of the upper layers of the adsorbents via air turbulence during centrifugation. Adsorbent portions could then be accurately weighed for isotherm, kinetic, and column purposes. At the time of weighing, an additional set of samples was weighed into tared vials, dried to a constant weight at $115^{\circ} \mathrm{C}$ to determine the moisture content (or \% dry adsorbent) for the particular batch of adsorbent. This method gave consistent dewatering results, the averages of which are included in Table 1 .

Salient features of the adsorbents are summarized in Table 1.

\section{Equilibrium studies}

Adsorption isotherms were determined by the batch, or bottle-point method, for all adsorbents. Varying, carefully determined, amounts of adsorbent were added to $120-\mathrm{ml}$ French square bottles containing $100 \mathrm{ml}$ of buffered adsorbate solution. The bottles were sealed and, together with appropriate controls, mechanically tumbled for a period of 8 days. Resultant solution concentrations were then determined, the equilibrium data from each such bottle representing one point on an adsorption isotherm.

\section{Kinetic studies}

Finite-bath, completely-mixed batch (CMB) reactor rate experiments were conducted for a number of adsorbents. using a 3-1. baffled 316-stainless-steel reactor, fitted with a twisted-blade type stirrer operating at $1200 \mathrm{rev} / \mathrm{min}$. The reactor was fitted with a sampling port incorporating a stainless steel needle valve and porous PTFE membrane (c. $10-\mu$ pore size) to enable the sampling of clear solution without interruption of the experiment. The rate experiments were normally conducted for a duration of $24 \mathrm{~h}$. Sample portions were $15 \mathrm{ml}$ each, representing $0.5 \%$ of the reactor volume. The cumulative volume change during the course of an experiment therefore was approximately $6 \%$, which was considered sufficiently small not to be taken into account during data analysis.

Table 1. Salient features of adsorbents

\begin{tabular}{|c|c|c|c|c|c|}
\hline Adsorbent & $\begin{array}{c}\text { B.E.T.* } \\
\text { surface } \\
\text { area }\left(\mathrm{m}^{2} \mathrm{~g}^{-1}\right)\end{array}$ & $\begin{array}{c}\text { Skeletal* } \\
\text { density, } \rho_{\mathrm{s}} \\
\text { (g dry adsorbent } \\
\mathrm{cm}^{-3} \text { solid matrix) }\end{array}$ & $\begin{array}{c}\text { Particle }+ \\
\text { density, } \rho_{\mathrm{p}} \\
\text { (g dry adsorbent } \\
\mathrm{cm}^{-3} \text { particle) }\end{array}$ & $\begin{array}{c}\text { Particle } \$ \\
\text { porosity } \\
\epsilon_{p}(-)\end{array}$ & $\begin{array}{l}\text { Average } \\
\text { per cent dry } \\
\text { adsorbent } \\
(\%)\end{array}$ \\
\hline \multicolumn{6}{|l|}{ Filtrasorb } \\
\hline 400 carbon & 1100 & 2.10 & 0.811 & 0.614 & NA \\
\hline BACM carbon & -1000 & 2.00 & 0.992 & 0.504 & NA \\
\hline Ambersorb XE-340 & 400 & 1.34 & 0.955 & 0.287 & 76.99 \\
\hline Ambersorb XE-347 & 350 & 1.85 & 1.038 & 0.439 & 70.39 \\
\hline Ambersorb XE-348 & 500 & 1.95 & 0.984 & 0.496 & 66.51 \\
\hline Amberlite XAD-2 & 300 & 1.06 & 0.582 & 0.451 & 56.39 \\
\hline Amberlite XAD-4 & 725 & 1.08 & 0.548 & 0.493 & $57.7 \pi$ \\
\hline Amberlite XAD-8 & 140 & 1.23 & 0.445 & 0.638 & 41.19 \\
\hline Duolite S-37| & - & $1.26+$ & 0.476 & 0.623 & 43.37 \\
\hline Duolite ES-863 & 400 & $1.16+$ & 0.676 & 0.416 & 61.94 \\
\hline
\end{tabular}

NA-not applicable.

* From manufacturers' literature.

+ Derived from $\uparrow$ and +

$\$$ Calculated on basis of water displacement by wetted, centrifuged particles.

$\$$ Derived from * + and $\$$; valid for adserbent particles in wetted state.

7) Derived on basis of water retention by wetted, centrifuged particles (see experimental procedures)

If Amine functionality, free-base form. 


\section{Column studies}

Fixed-bed downflow adsorber studies were conducted in $1-\mathrm{cm}$ (i.d.) glass columns. The experimental set-up consisted of five columns in parallel. Each column was fed by a multi-channel peristaltic pump (Gilson Minipuls II) from a glass storage reservoir at a fixed influent rate and concentration. Interconnective tubing and fittings were made of PTFE. Hourly effluents samples were taken by an automatic sampling device. Adsorber runs were typically conducted for a duration of $50 \mathrm{~h}$

\section{RESULTS AND DISCUSSION}

\section{Adsorption equilibria}

All the isotherm data generated in this study were mathematically described by an isotherm equation developed by Weber \& van Vliet (1979). The isotherm equation was found to provide excellent description of the data patterns encountered for all ten adsorbents. It was apparent from the outset that neither the Langmuir nor Freundlich equations would be sufficient for the broad range of systems and comprehensive objectives of this project. Other isotherm equations which would more adequately fit the broad range of equilibrium data than would the Freundlich or Langmuir equations are available; e.g. the three-parameter isotherm (Radke \& Prausnitz, 1972; Crittenden \& Weber, 1978). However, such isotherm equations pose a problem with respect to direct parameter evaluation because they express capacity, $q_{e}$, as an implicit function of solution concentration, $C_{e}$. A desirable property of an isotherm model in the context of batch rate and fixed-bed inodeling procedures is that it should be possible to arrange the equation explicitly in terms of concentration, i.e.

$$
\text { Concentration }=f(\text { Capacity }) \text {. }
$$

This precludes the need for the use of iterative search techniques when concentration must be determined for a given capacity for an isotherm equation rigidly implicit in terms of concentration.
The isotherm equation developed by Weber $\&$ Van Vliet (1979) has the form:

$$
C_{e}=a_{1} q_{e}^{\left(a_{2} q_{e}^{s}+a_{4}\right)}
$$

where

$$
\begin{aligned}
C_{e}= & \text { equilibrium solution concentration, } \\
& \mathrm{mg} \mathrm{I}^{-1} ; \\
q_{e}= & \text { corresponding adsorption capacity, } \\
& \mathrm{mg} \mathrm{g}^{-1} ; \\
\mathrm{a}_{i(i=1,4)=} & \text { coefficients determined by a multiple } \\
& \text { non-linear curve-fitting technique pre- } \\
& \text { dicated on the minimization of the } \\
& \text { sum of squares of residuals. }
\end{aligned}
$$

Figures 1-3 depict results from the isotherm studies. All the solid and dashed lines represent mathematical descriptions of the data (symbols), using the isotherm given in equation (2). The isotherm coefficients for equilibrium adsorption of phenol by all 10 adsorbents are in Table 2 . All isotherms are based on dry adsorbent weight.

The potential effect of initial phenol concentration on the position of the isotherm was specifically investigated. Only one adsorbent, Filtrasorb 400 , showed a discernible initial concentration-history effect for phenol, as indicated in Fig. 1. The adsorption capacity for an initial concentration of $100 \mathrm{mg} \mathrm{l}^{-1}$ was some $10 \%$ greater relative to the isotherm derived from the $1000 \mathrm{mg} \mathrm{l}^{-1}$ initial concentration data. A thorough verification was made to ensure that this was neither the result of a pH effect nor an analytical artifact. The phenomenologic bases underlying this observation are the subject of continued investigation.

Figure 2 illustrates, for BACM and Amberlite XAD-4 as examples, the absence of any discernible initial concentration effect for all adsorbents other than the Filtrasorb 400 . In that no initial concentration effect was observed for the BACM carbon, it appears that this phenomenon is not related to an

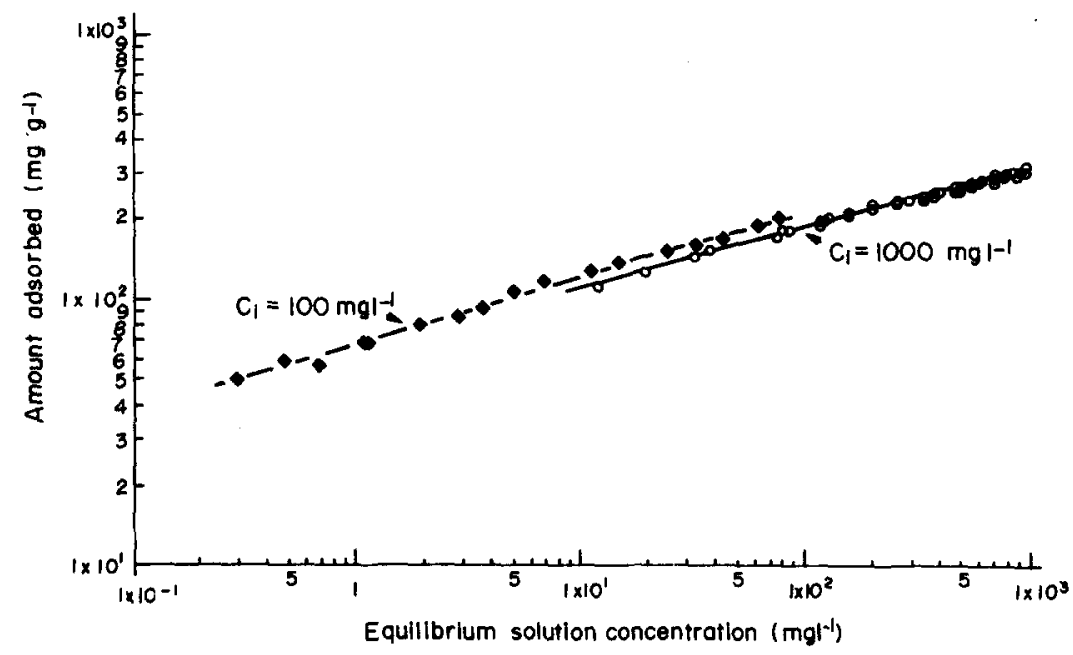

Fig. 1. Isotherms for phenol on Filtrasorb 400 activated carbon. The effect of initial solution concentration $\left(C_{i}\right)$ is illustrated. 


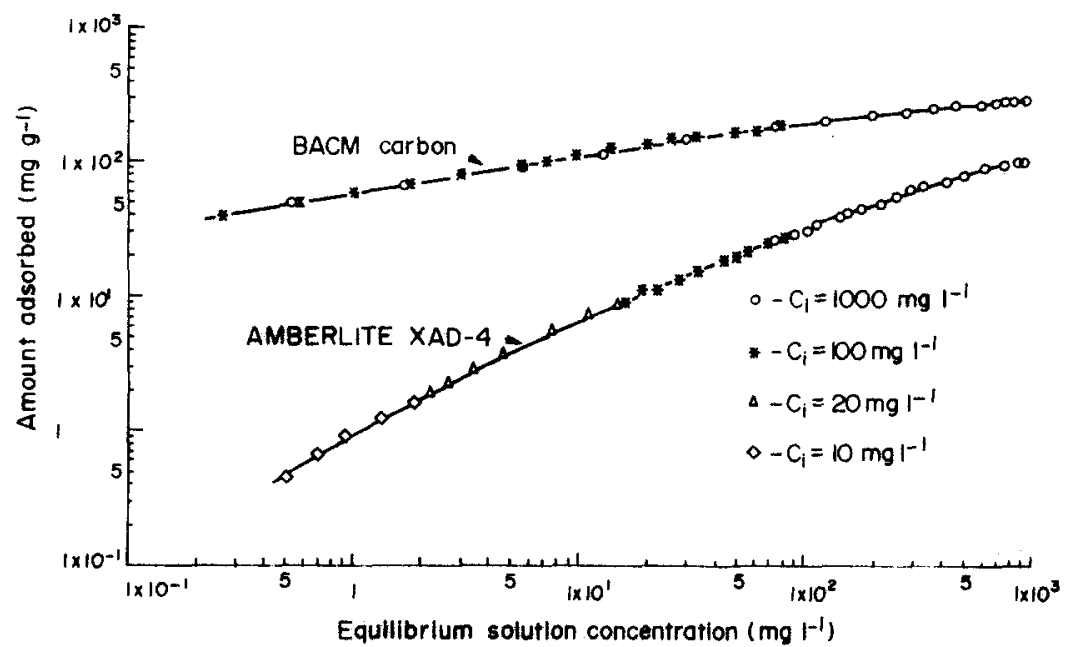

Fig. 2. Isotherms for phenol on BACM activated carbon and Amberlite XAD-4 polymeric adsorbent. The absence of any effect of initial solution concentration is to be noted.

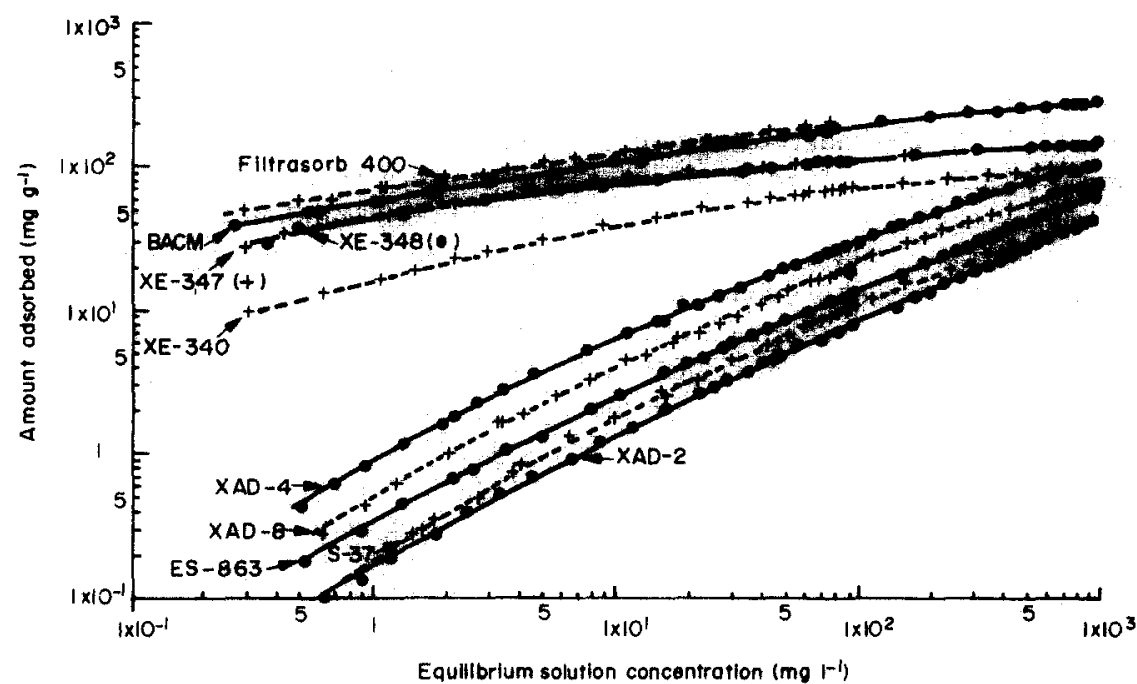

Fig. 3. Isotherms for phenol on various adsorbents. The solid and dashed lines represent the mathematical description of the data (by equation 2).

Table 2. Isotherm* coefficient values for phenol

\begin{tabular}{|c|c|c|c|c|}
\hline Adsorbent Coefficient & $a_{1}$ & $a_{2}$ & $a_{3}$ & $a_{4}$ \\
\hline $\begin{array}{l}\text { Filtrasorb } 400\left(100 \mathrm{mg} \mathrm{l}^{-1}\right) \\
\text { initial concentration }) \\
\text { Filtrasorb } 400\left(1000 \mathrm{mg} \mathrm{l}^{-1}\right.\end{array}$ & $0.1350 E-06$ & $0.3489 E-06$ & $0.2303 E+01$ & $0.3737 E+01$ \\
\hline initial concentration) & $0.2073 E-07$ & $0.2795 E-06$ & $0.2130 \mathrm{E}+01$ & $0.4237 \mathrm{E}+01$ \\
\hline BACM & $0.8975 E-06$ & $0.8536 E-07$ & $0.2643 E+01$ & $0.3434 \mathrm{E}+01$ \\
\hline Ambersorb XE-340 & $0.1908 \mathrm{E}-02$ & $0.1090 \mathrm{E}-03$ & $0.1878 E+01$ & $0.2239 \mathrm{E}+01$ \\
\hline Ambersorb XE-347 & $0.1192 \mathrm{E}-01$ & $0.8998 E-02$ & $0.1047 E+01$ & $0.6649 \mathrm{E}+00$ \\
\hline Ambersorb XE-348 & $0.2936 E-02$ & $0.4333 E-01$ & $0.7303 E+00$ & $0.8489 E+\infty 0$ \\
\hline Amberlite XAD-2 & $0.7202 E+01$ & $0.1621 E+00$ & $0.1806 \mathrm{E}+00$ & $0.9891 \mathrm{E}+00$ \\
\hline Amberlite XAD-4 & $0.1104 \mathrm{E}+01$ & $0.2240 \mathrm{E}+00$ & $0.2087 \mathrm{E}+00$ & $0.8573 E+00$ \\
\hline Amberlite XAD-8 & $0.2075 E+01$ & $0.2313 E+00$ & $0.2131 E+00$ & $0.8340 E+00$ \\
\hline Duolite S -37 & $0.5281 E+01$ & $0.4356 E+00$ & $0.1383 E+00$ & $0.6304 E+00$ \\
\hline Duolite ES-863 & $0.3383 \mathrm{E}+01$ & $0.4637 E+00$ & $0.8372 E-01$ & $0.7082 \mathrm{E}+00$ \\
\hline
\end{tabular}

- Isotherm equation: $C_{e}=\mathrm{a}_{1} q_{e}^{\left[\mathrm{a}_{2} q^{2}+\mathrm{a}_{4}\right]} ; C_{e}=\mathrm{mg}$ phevol $1^{-1} ; q_{t}=\mathrm{mg}$ phenol $\mathrm{g}^{-\mathrm{I}}$ dry adsorbent. After Weber \& van Vliet (1979) 
interaction of the adsorbate with an activated carbon per se.

The experimental and modeled isotherms for the adsorbents are given in Fig. 3. As a group, the carbons performed best, followed by the carbonaceous adsorbents, and finally the polymeric and resinous adsorbents. The differences are particularly pronounced at low phenol concentrations; at high concentrations (>1000 $\mathrm{mg} \mathrm{l}^{-1}$ ) projected capacities appear to converge. The concentration of a specific wastewater would thus seem to be of particular significance for selection of an adsorbent, at least in the case of phenol.

\section{Adsorption kinetics}

The rate data were analyzed by the method of Crittenden \& Weber (1978). Mass transport from solution to active adsorption sites within the porous adsorbents is presumed to take place according to the mechanism of film transport through the external hydrodynamic boundary layer coupled with intraparticle surface transport, motivated by an unsteady-state solid phase concentration gradient. The particles are considered spherical and structurally homogeneous. Local equilibrium is assumed to prevail at the carbon surface, and the bulk flow term in the diffusion equation is considered to be negligible. The effective intraparticle surface diffusion coefficient is considered to be independent of surface concentration, and to embody the effects of pore constriction and tortuosity.

The external film transfer coefficient, $k_{f b}$ and the effective intraparticle surface diffusion coefficient, $D_{k}$, are derived from the finite-bath rate data for each adsorbent by an iterative two-parameter search technique predicated on the minimization of the sum of squares of residuals. Each iteration involves the numeric solution of the coupled set of partial differential equations - with appropriate initial and boundary conditions-that describe the film and intraparticle transport mechanisms. Equations describing the adsorption mechanism are given in a subsequent section on adsorber columns.

Rate and column studies were conducted with both activated carbons, the three carbonaceous adsorbents, and one polymeric adsorbent, Amberlite XAD-4. These adsorbents were deemed to have sufficient adsorption capacity for phenol to merit continued investigation in terms of rate and column adsorber study. By way of example, the results from a CMB reactor rate study for one adsorbent, Ambersorb XE-340, are depicted in Fig. 4. The symbols in this figure represent experimental data, and the solid line represents the modeled curve from which the relevant rate parameters have been derived.

The film transfer coefficients and effective surface diffusion coefficients resulting from the $\mathrm{CMB}$ rate studies for phenol and the array of adsorbents, are listed in Table 3. Calculated ratios of the film transfer coefficient for each adsorbent relative to that for BACM activated carbon are included in Table 3.

It is evident from the data presented in Table 3 that the effective surface diffusion coefficient values cover quite a wide range; i.e. some 40 -fold difference exists between the highest (for the macroporous Amberlite XAD-4) and the lowest (for Ambersorb XE-340). As a group, the carbonaceous adsorbents have the lowest $D_{8}$ values, with the carbons being intermediate between the carbonaceous adsorbents and the polymeric adsorbent. The divergent values of $D_{a}$ for the various adsorbents underscore yet another facet of the differences between them.

In theory, for any adsorbent that is comprised of spherical beads with perfectly smooth exterior surfaces, the film transfer coefficient is expected to have a fixed value for a given set of experimental conditions. It is evident from the data in Table 3 that values for

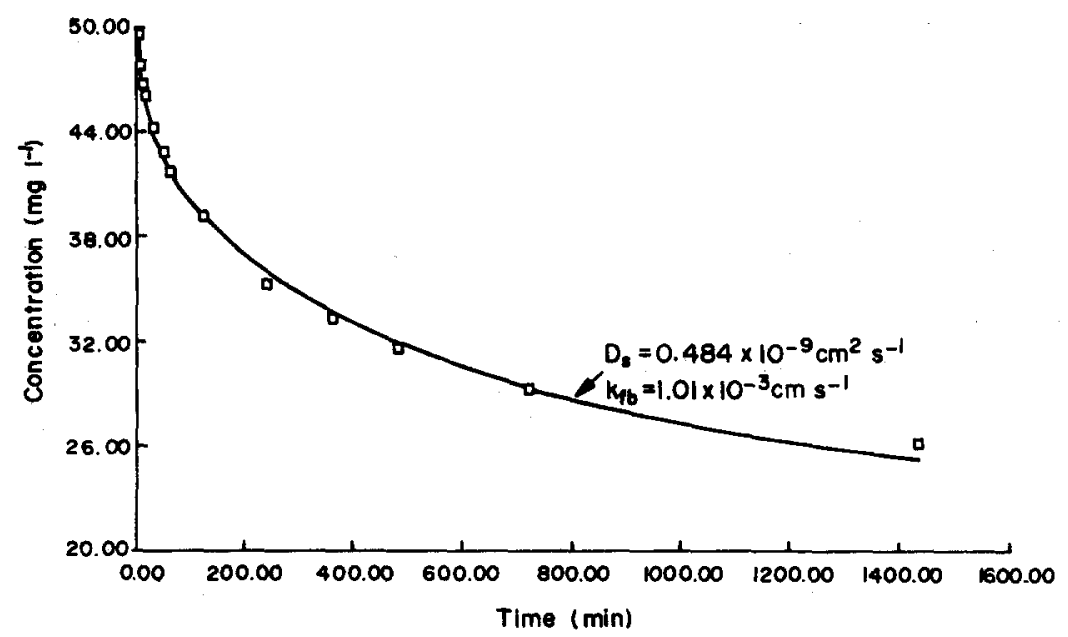

Fig. 4. Adsorption rate study for phenol on Ambersorb XE-340 in CMB reactor. (Stirrer speed $=1200 \mathrm{rpm}$; adsorbent particle size $=0.30-0.42 \mathrm{~mm}$; mass of dry adsorbent $=1.684 \mathrm{~g}$; reactor volume $=3 \mathrm{~L}$; solid line represents model description). 
Table 3. Finite bath* rate coefficients for phenol

\begin{tabular}{|c|c|c|c|}
\hline Adsorbent & $\begin{array}{c}\dagger \\
D_{s} \times 10^{9} \\
\left(\mathrm{~cm}^{2} \mathrm{~s}^{-1}\right)\end{array}$ & $\begin{array}{c}\ddagger \\
k_{f b} \times 10^{3} \\
\left(\mathrm{~cm} \mathrm{~s}^{-1}\right)\end{array}$ & $\begin{array}{c}\S \\
\text { Shape and } \\
\text { roughness factor, } \\
\eta \text {, dimensionless }\end{array}$ \\
\hline BACM carbon & 2.18 & 7.04 & 1.00 \\
\hline Filtrasorb 400 carbon 1 & 1.24 & 6.88 & 0.98 \\
\hline Ambersorb XE-348 & 0.696 & 4.88 & 0.69 \\
\hline Amberlite XAD-4 & 20.6 & 4.35 & 0.62 \\
\hline Ambersorb XE-347 & 0.572 & 1.32 & 0.19 \\
\hline Ambersorb XE-340 & 0.484 & 1.01 & 0.14 \\
\hline
\end{tabular}

* Stirrer speed $=1200 \mathrm{rpm}$; adsorbent particle size fraction: $0.30-0.42 \mathrm{~mm}$.

$+\mathrm{D}_{\mathrm{a}}$ : effective intraparticle surface diffusion coefficient.

$\ddagger k_{f b}$ : film transfer coefficient derived from CMB rate experiments.

$\S \eta$ : defined as the ratio of the $k_{f b}$ for a particular adsorbent to $k_{f b}$ for the BACM carbon.

I Based on the $100-\mathrm{mg}^{-1}$ initial concentration isotherm.

the CMB finite-bath film transfer coefficient, $k_{f b}$. for the various adsorbents differ markedly, ranging from a high of $7.04 \times 10^{-3} \mathrm{~cm} \mathrm{~s}^{-1}$ for BACM to a low of $1.01 \times 10^{-3} \mathrm{~cm} \mathrm{~s}^{-1}$ for Ambersorb XE-340. This is likely the result of the different exterior surface characteristics of the adsorbents. In particular, the external surface topography, or roughness, and shape of the particles will affect the character of the hydrodynamic boundary layer immediately adjacent to the surface. The value of $k_{f b}$ will thus also be influenced, in that the underlying definition of $k_{f}$ in the context of film theory is:

$$
k_{f}=\mathrm{D}_{1} / \delta
$$

where

$$
\begin{aligned}
\mathrm{D}_{1}= & \text { molecular diffusivity in aqueous solution, } \\
& {\left[\mathrm{L}^{2} \mathrm{~T}^{-1}\right] ; \text { and } } \\
\delta= & \text { conceptual thickness of the hydrodynamic } \\
& \text { boundary layer }[\mathrm{L}] .
\end{aligned}
$$

The decrease in $k_{f b}$ from the high values measured for the activated carbons to the low value for Ambersorb XE-340, follows a pattern that accords-at least qualitatively-with the observed topographical features of the adsorbents. The carbons have fairly rough surfaces, corresponding to the high $k_{f b}$ values. In spite of the more irregular granule shape for Filtrasorb 400 , both activated carbons have essentially the same $\eta$ value $(\eta \sim 1)$.

On the other end of the scale, Ambersorb XE-340 the carbonized polymer-has a shiny and polished appearance which readily identifies with the lowest $\eta$ value $(\eta=0.14)$. The $\eta$ values increase progressively for Ambersorb XE-347 to Ambersorb XE-348, seemingly as degree of carbonization increases. Ambersorb XE-348 beads have a dull appearance and an $\eta$ value of 0.69 , which is fairly close to that of carbon. It is noted with interest that the shape and roughness factor for the polymeric adsorbent Amberlite XAD-4 $(\eta=0.62)$ is close to that for the carbonized polymer Ambersorb XE-348 $(\eta=0.69)$.
It must be recognized that the method used to determine $k_{f b}$ is not a prima facie method for determination of surface roughness or topography; rather, the latter concept is derivative in nature. Inasmuch as the relative magnitudes of $k_{f b}$ for the various adsorbents are dependent on such system specific factors as the local hydrodynamic regimes adjacent to the adsorbent particles - which in turn is a function of reactor power input-the derived $\eta$ values likely do not represent absolute measures of discrete particle surface topography. Nevertheless, the sequence of values does reflect, on a relative scale, the character of a particle surface as it affects external mass transport dynamics. The shape and roughness factors, as derived from the CMB rate studies, can be put to good use in the calculation of corresponding film transport coefficients $\left(k_{f c}\right)$ for fixed-bed adsorption modeling procedures, as will shortly be demonstrated.

\section{Adsorber columns}

Modeling projections of column breakthrough patterns should ideally, if they are truly predictive, be predicated solely on parameters derived from independent equilibrium and kinetic studies and on given operating conditions. The column predictive modeling procedures of Crittenden \& Weber (1978) have been applied in this study. The fixed-bed adsorption model has essentially the same conceptual bases as those used for the CMB kinetic analysis, except for use of the appropriate liquid-phase continuity equation and associated initial and boundary conditions (Crittenden \& Weber, 1978), as given by the following set of equations.

$$
\begin{gathered}
\frac{\mathrm{D}_{\mathrm{s}}}{r^{2}} \frac{\partial}{\partial r}\left[r^{2} \frac{\partial q}{\partial r}\right]=\frac{\partial q}{\partial t} \\
\frac{v_{p} \partial c}{\partial z}+\frac{\partial c}{\partial t}+\rho_{p} \cdot \frac{(1-\epsilon)}{\epsilon} \cdot \frac{\partial q}{\partial t}=0
\end{gathered}
$$




$$
\begin{aligned}
& k_{f c}^{\prime}\left(c-c_{s}\right)=\left.\rho_{p} D_{s} \frac{\partial q}{\partial r}\right|_{r=R} \\
& k_{f c}^{\prime}\left(c-c_{s}\right)=\frac{\rho_{p}}{R^{2}} \frac{\partial}{\partial t} \int_{0}^{R} q r^{2} \mathrm{~d} r \\
&\left.\frac{\partial q}{\partial r}\right|_{\substack{r=0 ; t,\left.2 \\
q\right|_{t=0 ; z, r}}}=0 \\
&\left.c\right|_{t=0 ; z}=0 \\
&\left.c\right|_{\substack{z=0 \\
i>0}}=c_{0}(t) \\
& k_{f c}^{\prime}=k_{f c} \cdot \eta
\end{aligned}
$$

where

$c=$ solution phase concentration, $\left(\mathrm{ML}^{-3}\right)$;

$c_{0}=$ adsorber influent concentration, $\left(\mathrm{ML}^{-3}\right)$;

$c_{z}=$ solution phase concentration at the particle surface, $\left(\mathrm{ML}^{-3}\right)$;

$D_{1}=$ effective intraparticle surface diffusion coeffcient, $\left(\mathrm{L}^{2} \mathrm{~T}^{-1}\right)$;

$k_{f b}=\mathrm{CMB}$ derived film transfer coefficient, ( $\left.\mathrm{LT}^{-1}\right)$ );

$k_{f c}=$ correlation derived film transfer coefficient for adsorber, $\left(\mathrm{LT}^{-1}\right)$;

$k_{j c}^{\prime}=$ adjusted film transfer coefficient for adsorber, $\left(\mathrm{LT}^{-1}\right)$;

$q=$ solid phase concentration, $\left(\mathrm{MM}^{-1}\right)$;

$r=$ particle radial coordinate, $(\mathrm{L})$;

$R=$ particle radius, $(\mathrm{L})$

$t=$ time, $(T)$;

$v_{i}=$ adsorber interstitial fluid velocity, $\left(\mathrm{LT}^{-1}\right)$;

$z=$ adsorber longitudinal coordinate, (L);

$\epsilon=$ adsorber void fraction, (dimensionless);

$\eta=$ particle shape and surface topography factor, (dimensionless); and

$\rho_{p}=$ particle density, $\left(\mathrm{ML}^{-3}\right)$.

Equations (4) and (5) represent the solid and liquid phase continuity equations respectively. Equations (6) through (11) represent the boundary and initial conditions. The adjusted film transfer coefficient, as given in equation (12) was used for adsorber predictive modeling procedures.

Fixed-bed downflow adsorber runs were conducted with phenol for both carbons, the three carbonaceous adsorbents, and the polymeric adsorbent, Amberlite XAD-4. The results of these runs are depicted in Fig. 5, in which the symbols represent column effluent concentration data. The finite bath $D_{s}$ values derived from the CMB rate studies were used as such for the corresponding model predictions for the breakthrough curves, represented by the solid lines. Baseline values of the external film transfer coefficients $\left(k_{f c}\right)$ applicable to column operation, were calculated for the various column systems using the mass transfer correlation of Williamson et al. (1963):

$$
k_{\text {fc }}=2.4 R e^{-0.66} S c^{-0.58} v_{\mathrm{s}}(0.08<R e<125)
$$

where

$$
\begin{aligned}
R e & =\frac{\rho R v_{\mathrm{s}}}{\epsilon \mu} \\
S c & =\frac{\mu}{\rho \mathrm{D}_{1}} \\
\mathrm{v}_{\mathrm{s}} & =\text { superficial fluid velocity, }\left(\mathrm{LT}^{-1}\right) ; \\
\rho & =\text { fluid density, }\left(\mathrm{ML}^{-3}\right) ; \\
\mu & =\text { fluid viscosity, }\left(\mathrm{ML}^{-1} \mathrm{~T}^{-1}\right) ;
\end{aligned}
$$

and other symbols as defined before.

The baseline $k_{f c}$ values were multiplied by the appropriate shape and roughness factor, $\eta$, derived from the CMB rate studies to incorporate the effects of particle surface topography into the column mass transfer rate equation (equation 12). Normalization was done with respect to the BACM spherical carbon. The various rate coefficients and salient data pertaining to the column runs are summarized in Table 4.

These data were used as input for the modeling procedures, the results of which are graphically depicted (as solid lines) in Fig. 5. For the breakthrough profiles in Fig. 5, the ordinate represents the ratio of adsorber effluent concentration to influent concentration. The abscissa represents throughput units, where one throughput is defined as the amount of fluid that contains sufficient solute to completely saturate the adsorber bed at the given influent level if complete removal of the solute were to be achieved.

where

$$
T_{\mathrm{s}}=t / \tau \mathrm{D}_{\mathrm{G}}
$$

$$
\begin{aligned}
\mathrm{D}_{\mathrm{G}}= & \rho_{p} q_{\mathrm{e}}(1-\epsilon) /\left(\epsilon c_{0}\right) \text { (dimensionless); } \\
T_{\mathrm{s}}= & \text { throughput parameter; } \\
q_{e}= & \text { equilibrium solid phase concentration for a } \\
& \text { solution phase concentration of } c_{0}, \\
& \left(\mathrm{MM}^{-1}\right) ; \\
\tau= & \text { interstitial hydraulic residence time, }(\mathrm{T}) ;
\end{aligned}
$$

and other symbols as defined before.

It is apparent from Fig. 5 that good agreement was achieved between predicted and experimental breakthrough curves for the synthetic adsorbents. For these adsorbents, the modeling procedure successfully accommodates a diverse array of rate and equilibrium parameters. In particular, incorporation of the shape and roughness factors into the external mass transfer rate equation appears efficacious.

For the two activated carbons, the predicted and experimental breakthrough profiles correspond well for about the first half of the curves. This suggests that the values for the film transport coefficient-the influence of which is initially dominant-are welldefined, and that the intraparticle surface diffusion coefficients hold well for some $80 \%$ of saturation capacity (at the given influent concentration). Thereafter the experimental breakthrough profiles for both carbons appear to enter a second stage of comparatively 

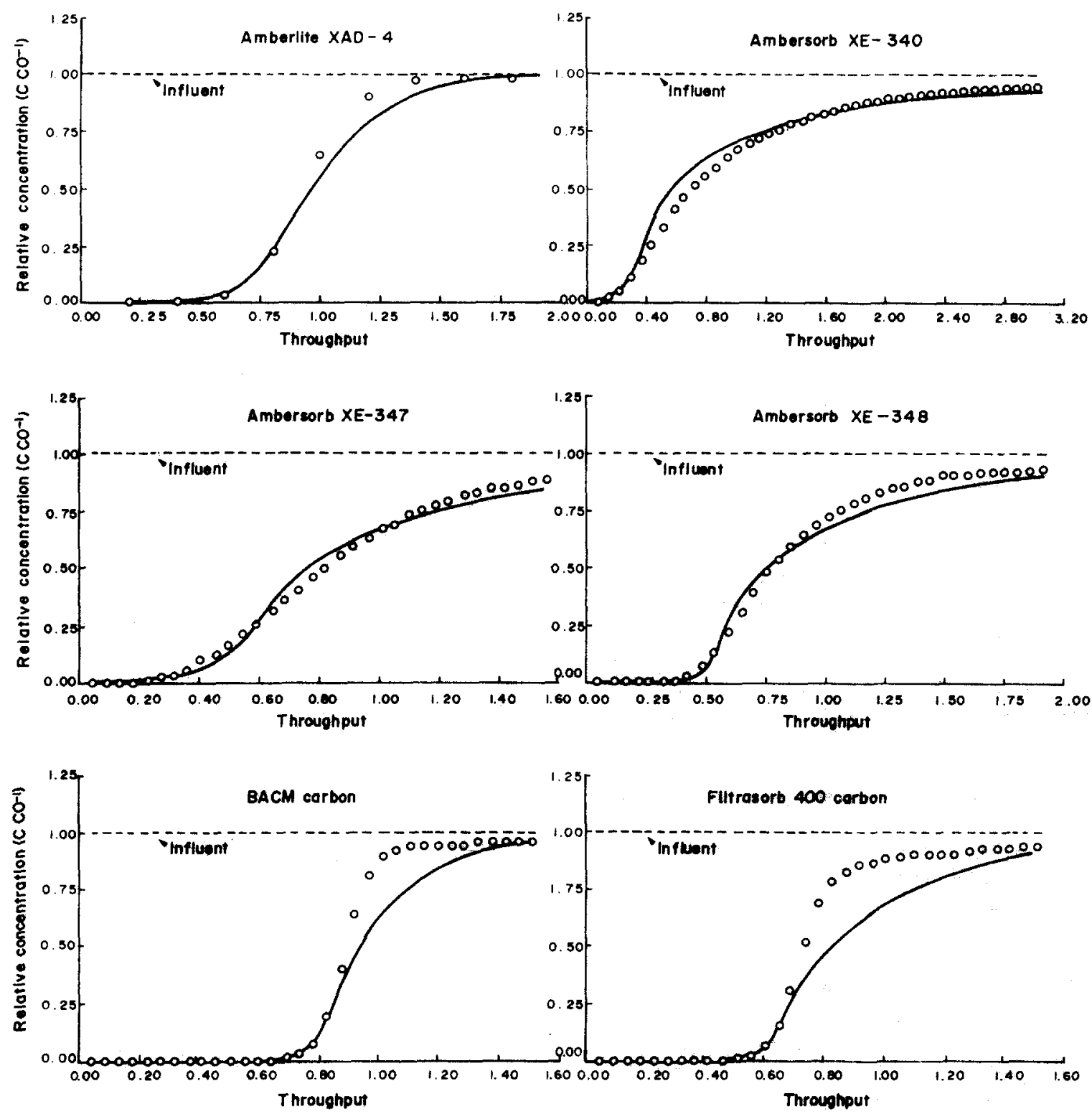

Fig. 5. Fixed-bed adsorber breakthrough profiles for phenol and a variety of adsorbents. Experimental data are represented by symbols, and predicted profiles by solit lines. kate coefficient values and salient operational data are summarized in Table 4.

slow approach to equilibrium, not totally accountod for in the present modeling procedure. The experimental breakthrough curves for the two carbons form slightly inclined plateaus which extend well beyond even the throwhout limits depicted in Fig 5. This observation is not indicative of development of biological activity in the columns at extendod times of operation and/or throughput, for any signifeant development of biological activity should actually cause a decrease in concentration breakthrough from the adborbers. Rather, the data are sumoutive of a datine in intraparticle dufusion rate during the latter part of breakthrough, as saturation is approached.
The phenomenon of unexpectedly gradual approach to equilibrium during the latter part of brealathrough for the carbons is most probelty not the result of a consentration-dependent surface diffusion cocficient, as mint at first be surnized. The fact that adsorbate molecules would be inclined to become more mobile as surface concentration increases argues against this; i.e. the diffubional activation energy will decrease as surface concentration increnses $A$ more likely explanation is believed to

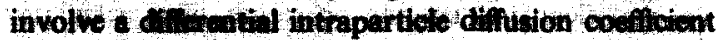
within a bil we pore size didribution (Bucholz \& Krückels, 1976; Nerethieks, 1976; Ruckenstein et al., 
Table 4. Salient data* pertaining to column runs

\begin{tabular}{|c|c|c|c|c|c|c|}
\hline \multirow{2}{*}{ Parameters } & \multirow[b]{2}{*}{ BACM } & \multirow{2}{*}{$\begin{array}{c}\text { Filtrasorb } \\
400\end{array}$} & \multirow{2}{*}{$\begin{array}{c}\text { Amberlite } \\
\text { XAD-4 }\end{array}$} & \multicolumn{3}{|c|}{ Ambersorb } \\
\hline & & & & XE-340 & XE-347 & XE-348 \\
\hline Bed depth (cm) & 5.95 & 7.30 & 15.60 & 8.80 & 6.50 & 6.35 \\
\hline Flowrate $\left(\mathrm{ml} \mathrm{min}^{-1}\right)$ & 5.51 & 5.46 & 5.74 & 5.97 & 5.03 & 5.27 \\
\hline Interstitial contact & 0.426 & 0.582 & 0.708 & 0.445 & 0.370 & 0.354 \\
\hline \multicolumn{7}{|l|}{ time (min) } \\
\hline Bed porosity & 0.514 & 0.568 & 0.340 & 0.394 & 0.373 & 0.383 \\
\hline Influent concentration ( $\mathrm{mg} \mathrm{l}^{-1}$ ) & 50.2 & 50.0 & 49.4 & 49.3 & 49.9 & 50.4 \\
\hline D. $\times 10^{9}\left(\mathrm{~cm}^{2} \mathrm{~s}^{-1}\right)$ & 2.18 & 1.24 & 20.6 & 0.484 & 0.572 & 0.696 \\
\hline$k_{f s} \times 10^{3}$ (baseline) $\dagger\left(\mathrm{cm} \mathrm{s}^{-1}\right)$ & 9.06 & 9.65 & 6.99 & 7.81 & 7.08 & 7.36 \\
\hline$k_{f c}^{\prime} \times 10^{3}$ (incorporating & 9.06 & 9.46 & 4.33 & 1.09 & 1.35 & 5.08 \\
\hline $\begin{array}{l}\text { shape and roughness } \\
\text { factor, } \eta)\left(\mathrm{cm} \mathrm{s}^{-1}\right)\end{array}$ & & & & & & \\
\hline
\end{tabular}

* All for phenol as solute.

$\dagger$ Using correlation of Williamson et al. (1963).

1971). In this perspective the adsorbent is perceived to possess macro and transitional pores which are readily accessible to solute molecules. Mass transport in these pores may proceed comparatively rapidly. Conversely, within the micropore category of a bidisperse pore size distribution, diffusion may be severely retarded due to steric interactions, depending on the relative sizes of the solute molecules and the micropores. Buchholz \& Krückels (1976) have derived a micropore surface diffusion coefficient of $2 \times 10^{-15} \mathrm{~cm}^{2} \mathrm{~s}^{-1}$ for 2,4-dichlorophenol on an activated carbon, and have likened the micropore transport to solid diffusion. (The corresponding macropore surface diffusion coefficient value was on the order of $3-6 \times 10^{-8} \mathrm{~cm}^{2} \mathrm{~s}^{-1}$ ). Although macro- and micropore diffusion will proceed in parallel, these mechanisms could effectively be regarded to occur sequentially if the micropore transport is significantly retarded; i.e. quasi-saturation could be achieved in macro (and transitional) pores fairly rapidly, followed by a slow approach to equilibrium via micropore transport. Should solute molecules of a particular type and size be unable to penetrate the micropore system, intraparticle transport will essentially be a single-stage process. The type of mechanism that will ultimately manifest will therefore be dependent on the particular adsorbent and solute combination. For example, as noted in Fig. 6, the fixed-bed adsorption of p-toluene sulfonate on Filtrasorb 400 is forecasted well by the current modeling procedure, which presumes a homogeneous intraparticle structure. The experimental procedures and the derivation of corresponding rate parameters for the p-toluenesulfonate were essentially the same as those employed for phenol.

\section{SUMMARY AND CONCLUSIONS}

Widely differing adsorption isotherms were obtained for phenol on a series of synthetic adsorbents and two activated carbons. Generally, the activated carbons performed best, followed by the

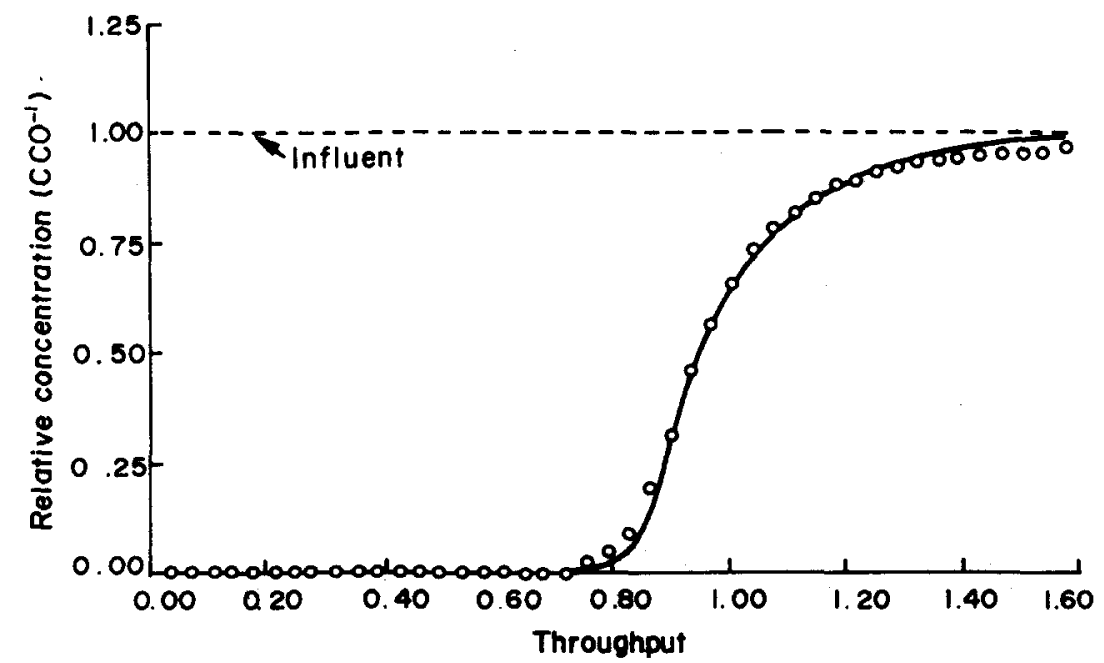

Fig. 6. Fixed-bed adsorber breakthrough profile for p-toluenesulfonate and Filtrasorb 400 activated carbon. (Bed depth $=10.6 \mathrm{~cm}$; flowrate $=5.5 \mathrm{ml} \mathrm{min}^{-1}$; influent concentration $=14.8 \mathrm{mg} \mathrm{l}^{-1}$; interstitial contact time $=0.80 \mathrm{~min} ; \mathrm{D}_{\mathrm{s}}=2.3 \times 10^{-9} \mathrm{~cm}^{2} \mathrm{~s}^{-1} ; k_{f c}^{\prime}=8.48 \times 10^{-3} \mathrm{~cm} \mathrm{~s}^{-1}$. Experimental data are represented by symbols, and the predicted profile by a solid line.) 
carbonaceous adsorbents, and finally by the polymeric and resinous adsorbents. The shapes of the isotherms suggest that the polymeric and resinous adsorbents may be most competitive with activated carbons at very high waste concentrations, at least for phenol. An isotherm equation recently developed by Weber \& van Vliet (1979) was found to successfully accommodate all the isotherm data patterns encountered for the various adsorbents as well as provide explicit characterization of solution concentration as a function of adsorbent capacity, a significant factor for use in modeling and design procedures.

Completely mixed batch reactor rate studies with phenol and a selection of six of the adsorbents yielded a diverse array of exterior film transport coefficients, $k_{f b}$, and intraparticle surface diffusion coefficients $D_{g}$. A macroporous polymeric adsorbent exhibited the highest $D_{8}$ value; the activated carbons intermediate values, and the carbonaceous adsorbents the lowest $D_{s}$ values. The fairly wide range of $k_{f b}$ values obtained led to the derivation of a particle shape and roughness factor, $\eta$, which describes the effect of particle surface topography on external mass transfer dynamics.

Experimental breakthrough profiles resulting from fixed-bed adsorber studies were compared with predicted curves predicated on the equilibrium and rate parameters derived from the batch equilibrium and rate studies. The particle shape and roughness factors were also incorporated in the rate equations for fixedbed adsorber modeling. The modeling procedure successfully predicted breakthrough curves for the synthetic adsorbents. For the activated carbons, a good agreement was attained between predicted and experimental curves up to some $80 \%$ of saturation, or about the first half of the concentration breakthrough curve. A gradual approach to equilibrium during the latter part of breakthrough observed for the carbons suggests differential intraparticle diffusion coefficients within a bidisperse pore size distribution. The overall modeling procedure is considered to have been generally efficacious and to have adequately predicted system performance for a diverse array of adsorbents over ranges of breakthrough which are of practical significance for water and wastewater treatment applications.

Acknowledgements-The authors express appreciation to Mr Sun Liang for his able assistance on portions of the laboratory work described in the paper. Partial support for this research-which was conducted in the Environmental and Water Resources Engineering Laboratories of the University of Michigan-was provided by the National Institute for Water Research of the Republic of South Africa in the form of a Predoctoral Fellowship to B. M. van Vliet, and by the Ministry of Education of Japan in the form of a Postdoctoral Fellowship to $H$. Hozumi. The work was further supported, in part, by Research Grant ENG 77-25696, Urban and Environmental Engineering, Division of Engineering, U.S. National Science Foundation. Mention of commercial products does not constitute endorsement or recommendation for use.

\section{REFERENCES}

Buchholz H. \& Krückels W. (1976) Sorptionskinetik gelöster organischer Substanzen an Aktiukohlen. Verfahrenstechnik 10, 290-296.

Chriswell C. D., Ericson R. L., Junk G. A., Lee K. W., Fritz J. S. \& Svec H. J. (1977) Comparison of macroreticular resin and activated carbon as sorbents. J. Am. Wat. Wks Ass. 69, 669-674.

Crittenden J. C. \& Weber Jr W. J. (1978) Predictive model for design of fixed-bed adsorbers: parameter estimation and model development. J. envir. Engng Div., Am. Soc. Civ. Engnrs 104, EE2: 185.

Diamond Shamrock Chemical Co. (1973) Conditioning ion exchange resins before use. Duolite Technical Sheet 105, Diamond Shamrock Chemical Co., Redwood City, CA.

Gauntlett R. B. (1975) A comparison between ion-exchange resins and activated carbon for the removal of organics from water. Water Research Center Technical Report TR 10, Medmenham, England.

Junk G. A., Richard J. J., Svec H. J. \& Fritz J. S. (1976) Simplified resin sorption for measuring selected contaminants. J. Am. Wat. Wks Ass. 68, 218-222.

Kennedy D. C. (1973) Macroreticular polymeric adsorbents. Ind. Engng Chem. Prod. Res Dev. 12, 56-61.

Kim B. R., Snoeyink V. L. \& Saunders F. M. (1976) Adsorption of organic compounds by synthetic resins. $J$. Wat. Pollut. Control Fed. 48, 120-133.

Kunin R. (1976) The use of macroreticular polymeric adsorbents for the treatment of waste effluent. Pure Appl. Chem. 46, 205-211.

Leenheer J. A. \& Huffman Jr E. W. D. (1976) Classification of organic solutes in water using macroreticular resins. $J$. Res. U.S. Geol. Sur. 4, 737-751.

Neely J. W. (1978) A model for the removal of trihalomethanes from water by Ambersorb XE-340. Proceedings 176th ACS Meeting: Activated Carbon Adsorption of Organics from the Aqueous Phase, Miami, FL.

Neretnieks I. (1976) Analysis of some adsorption experiments with activated carbon. Chem. Engng. Sci. 31, 1029-1035.

Radke C. J. \& Prausnitz J. M. (1972) Adsorption of organic solutes from dilute aqueous solution on activated carbon. Ind. Engng Chem. Fund. 11, 445-451.

Rohm \& Haas Co. (1978). Technical Bulletin Amberlite XAD-4. Rohm \& Haas Technical Bulletin, Philadelphia, PA.

Rosenbaum J. L. (1975) Resin hemoperfusion in the treatment of acute drug intoxication. Ind. Engng Chem., Prod. Res. Dev. 14, 99-101.

Ruckenstein E., Vaidyanathan A. S. \& Youngquist G. R. (1971) Sorption by solids with bidisperse pore structures. Chem. Engng Sci. 26, 1305-1318.

Weber Jr W. J. \& van Vliet B. M. (1979) A general isotherm explicit in terms of solution concentration. Technical Memorandum EWRE-010379, Environmental and Water Resources Engineering Laboratories, The University of Michigan, Ann Arbor, MI.

Williamson J. E., Bazaire K. E. \& Geankoplis C. J. (1963). Liquid-phase mass transfer at low Reynolds Numbers. I \& EC Fund. 2, 126-129.

Wood P. R. (1979) Treatment of contaminated ground water. Proceedings, EPA/NATO/CCMS Conference: Adsorption Techniques, Washington, DC. 